CLINICAL STUDY

\title{
Adiponectin oligomers as potential indicators of adipose tissue improvement in obese subjects
}

\author{
Anna De Rosa ${ }^{1}$, Maria Ludovica Monaco ${ }^{1,2}$, Mario Capasso ${ }^{1,3}$, Pietro Forestieri ${ }^{4}$, Vincenzo Pilone ${ }^{4}$, \\ Carmela Nardelli ${ }^{1,3}$, Pasqualina Buono ${ }^{2,5}$ and Aurora Daniele ${ }^{2,6}$ \\ ${ }^{1}$ CEINGE Biotecnologie Avanzate Scarl, Via Gaetano Salvatore 486, 80145 Naples, Italy, ${ }^{2}$ IRCCS Fondazione SDN, Naples, Italy, ${ }^{3}$ Dipartimento di \\ Biochimica e Biotecnologie Mediche, Università degli Studi di Napoli Federico II, Naples, Italy, ${ }^{4}$ Dipartimento di Chirurgia Generale, Geriatrica, Oncologica \\ e Tecnologie Avanzate, Università degli Studi di Napoli Federico II, Naples, Italy, ${ }^{5}$ Dipartimento di Studi delle Istituzioni e dei Sistemi Territoriali, Facoltà di \\ Scienze Motorie, Università degli Studi di Napoli Parthenope, Naples, Italy and ${ }^{6}$ Dipartimento di Scienze e Tecnologie Ambientali Biologiche Farmaceutiche, \\ Seconda Università degli Studi di Napoli, Caserta, Italy
}

(Correspondence should be addressed to A Daniele who is now at CEINGE Biotecnologie Avanzate Scarl; Email: aurora.daniele@unina2.it)

\begin{abstract}
Objective: Adiponectin is an adipocytokine that exerts beneficial effects on obesity and related disorders by two receptors (ADIPORs). Adiponectin is produced as a monomer that circulates in serum as different oligomers. The oligomerization state and the tissue expression of adiponectin and ADIPORs are linked to its biological activities. In this study, the levels of total adiponectin and its oligomers were evaluated in relation to obesity and surgical weight loss. The expression of adiponectin and ADIPORs was analyzed in visceral and subcutaneous adipose tissues of obese patients.

Design and methods: In 25 obese patients and 44 age- and sex-matched controls, the serum levels of adiponectin and its oligomers were measured and compared by ELISA, western blotting, and gel filtration. The expression of adiponectin and ADIPORs in both adipose tissues was evaluated by realtime quantitative PCR and western blotting.

Results: The amount of each adiponectin oligomer, including the monomer, increases after weight loss. The reduced circulating levels of adiponectin and its oligomers are not associated with the adipose tissue depot-specific expression of adiponectin and ADIPORs.

Conclusions: Our results suggest that in patients, adiposity is associated with the serum concentrations of adiponectin and its oligomers but not with adipose tissue depot-specific expression of adiponectin and ADIPORs. In particular, the increase in adiponectin monomer levels could probably be related to the improvement of the whole-body energy metabolism then being involved in the improvement of adipose tissue function after weight loss. This work indicates the importance of assessing the whole adiponectin oligomeric profile as further potential indicators of adipose tissue functions in obesity.
\end{abstract}

European Journal of Endocrinology 169 37-43

\section{Introduction}

Adipocyte complement-related protein of $30 \mathrm{kDa}$, namely adiponectin (ACRP30 or ADIPOQ), is produced by adipocytes and circulates at very high levels; it exerts many beneficial effects on obesity and related diseases ranging from metabolic syndrome to malignancies (1). ACRP30 is synthesized as a monomer that forms different oligomeric complexes: a trimer of low molecular weight (LMW), a hexamer of medium molecular weight (MMW), and a multimer of high molecular weight $(\mathrm{HMW})(1,2)$. ACRP30 exerts its effects by two specific and widely expressed receptors, ADIPOR1 and ADIPOR2 $(2,3,4)$. A third potential receptor is represented by T-cadherin (4). Distinct biological activities are associated with the different ACRP30 oligomers even if the physiological role of each form needs to be further elucidated (5). Numerous studies have demonstrated a strong correlation of HMW oligomers with several metabolic abnormalities $(6,7,8,9)$, while the role of MMW oligomers and even less of LMW oligomers was poorly investigated $(10,11)$. Furthermore, a biologically active fragment of ACRP30 (gACRP30) that increases lipid oxidation and lowers plasma glucose levels was reported $(5,12,13)$. However, a pro-inflammatory as well as an anti-inflammatory role of gACRP30 was reported (14).

Obesity is a large and growing health problem that represents a risk factor for the development of several pathologies including cancer $(15,16)$. The severity of obesity is highly related to the accumulation and distribution of body fat; in fact, visceral obesity is more correlated with insulin resistance, coronary artery diseases, as well as metabolic diseases compared with subcutaneous obesity (17). Furthermore, visceral and subcutaneous adipose tissues (VAT and SAT) are morphologically and functionally different, with VAT 
Table 1 Comparison of anthropometric and biochemical data between controls and obese subjects. Data are expressed as mean \pm s.D.

\begin{tabular}{lccc}
\hline Parameters & $\begin{array}{c}\text { Controls } \\
(n=44)\end{array}$ & $\begin{array}{c}\text { Obese } \\
(n=25)\end{array}$ & $\begin{array}{c}\boldsymbol{P} \\
\text { value }^{\mathrm{a}}\end{array}$ \\
\hline Age (years) & $39.3 \pm 14.0$ & $34.9 \pm 10.5$ & $\mathrm{NS}$ \\
Sex: male/female & $20 / 24$ & $12 / 13$ & $\mathrm{NS}$ \\
BMl $\left(\mathrm{kg} / \mathrm{m}^{2}\right)$ & $23.5 \pm 3.4$ & $45.6 \pm 9.0$ & $<0.01$ \\
Systolic blood pressure & $116.4 \pm 4.6$ & $132.6 \pm 5.9$ & $\mathrm{NS}$ \\
$\quad(\mathrm{mmHg})$ & & & \\
Diastolic blood pressure & $80.5 \pm 3.8$ & $88.3 \pm 7.8$ & $\mathrm{NS}$ \\
$\quad(\mathrm{mmHg})$ & & & \\
Total cholesterol $(\mathrm{mg} / \mathrm{dl})$ & $199.9 \pm 39.7$ & $195.9 \pm 39.2$ & $\mathrm{NS}$ \\
HDL-cholesterol $(\mathrm{mg} / \mathrm{dl})$ & $54.5 \pm 17.2$ & $52.1 \pm 5.7$ & $\mathrm{NS}$ \\
LDL-cholesterol $(\mathrm{mg} / \mathrm{dl})$ & $128.3 \pm 32.5$ & $118.9 \pm 30.7$ & $\mathrm{NS}$ \\
Triglycerides $(\mathrm{mg} / \mathrm{dl})$ & $104.8 \pm 64.7$ & $122.1 \pm 49.0$ & $\mathrm{NS}$ \\
AST $(\mathrm{U} / \mathrm{l})$ & $20.1 \pm 7.3$ & $24.3 \pm 11.7$ & $\mathrm{NS}$ \\
ALT $(\mathrm{U} / \mathrm{l})$ & $21.6 \pm 14.3$ & $40.1 \pm 39.0$ & $<0.05$ \\
Glucose $(\mathrm{mg} / \mathrm{dl})$ & $80.9 \pm 11.2$ & $84.5 \pm 12.6$ & $\mathrm{NS}$ \\
Total ACRP30 $(\mu \mathrm{g} / \mathrm{ml})$ & $28.9 \pm 9.4$ & $8.1 \pm 3.6$ & $<0.01$ \\
HMW ACRP30 $(\mu \mathrm{g} / \mathrm{ml})$ & $4.4 \pm 2.2$ & $5.9 \pm 3.7$ & $<0.05$ \\
\hline
\end{tabular}

The statistical significance was established at $P<0.05$. NS, not significant AST, aspartate aminotransferase; ALT, alanine aminotransferase.

aMann-Whitney $U$ test.

producing greater amounts of bioactive proteins, being more sensitive to lipolytic stimuli and highly deregulated in obesity and related disorders compared with SAT $(1,18)$. Previous data on ADIPOQ expression in relation to AT tissues are conflicting $(19,20,21)$ even if increased $A D I P O Q$ mRNA levels have been found in VAT vs SAT in animal models $(22,23)$.

Together with the well-known endocrine role of ACRP30, an autocrine/paracrine role has also been suggested (24); in fact, both ACRP30 receptors have been identified in adipose tissues, but their relative expression in VAT and SAT remains to be defined $(25,26)$.

In morbid obesity, surgery is the most suitable approach to obtain significant weight loss and beneficial metabolic effects as well as improvement of ACRP30 levels (27). However, few studies with conflicting results correlated weight loss with the distribution of each ACRP30 oligomer $(28,29)$.

In this work, we evaluated the levels of total ACRP30 and the distribution of its oligomers in relation to the anthropometrical and biochemical features of severely obese patients and of a subgroup of them subjected to bariatric surgery. The results were compared with age- and sex-matched control subjects. In addition, we investigated the expression of $A D I P O Q$, ADIPOR 1 , and ADIPOR2 at mRNA and protein levels in VAT compared with SAT of severely obese subjects.

\section{Materials and methods}

\section{Subjects and sampling}

Twenty-five severely obese subjects (BMI: 45.6 $\pm 9.0 \mathrm{~kg} / \mathrm{m}^{2}$ ) were recruited from the Obesity Surgery
Clinic of Federico II University. All patients were subject to laparoscopic gastric banding. Patients with type 2 diabetes mellitus were not included in the study. Forty-four healthy age-matched volunteers were recruited as lean controls. For 19 patients, VAT, SAT, and serum samples were collected at the time of the bariatric surgery; for six patients, serum samples were collected and analyzed preoperatively (TO) as well as 12 months after the surgery (T1). Both tissues and serum samples were collected after a 12-h overnight fasting period, immediately frozen in liquid nitrogen, and stored at $-80{ }^{\circ} \mathrm{C}$ to extract RNA and/or proteins. The study was approved by the Ethics Committee of our Faculty of Medicine and was conducted in accordance with the ethical principles stated in the most recent version of the Declaration of Helsinki. Informed consent was obtained from each patient and each volunteer.

\section{Anthropometric and biochemical measurements}

The anthropometric and biochemical features of total study participants are given in Tables 1 and 2. BMI was calculated as reported previously (6), and the percentage of excess weight loss (\% EWL) was calculated as the weight loss $(\mathrm{kg})$ after the surgery divided by the TO weight $(\mathrm{kg})$ per 100 . For all participants, total cholesterol, HDL, LDL, triglyceride, glucose, aspartate transaminase (AST), and alanine transaminase (ALT) levels were measured. Total serum ACRP30 was measured by ELISA method using a house-produced polyclonal antibody as described $(6,7)$; the amount of HMW oligomers was detected by a commercial kit (Millipore, Billerica, MA, USA) as reported $(6,7)$. Each serum sample was tested three times in triplicate.

Table 2 Comparison of anthropometric and biochemical data in obese patients before (TO) and after (T1) the surgery. Data are expressed as mean \pm s.D.

\begin{tabular}{lccc}
\hline Parameters & T0 $(n=6)$ & T1 $(n=6)$ & $\boldsymbol{P}_{\text {value }}$ \\
\hline Weight $(\mathrm{kg})$ & $122.2 \pm 28.7$ & $79.3 \pm 21.9$ & $<0.01$ \\
BMI $\left(\mathrm{kg} / \mathrm{m}^{2}\right)$ & $42.5 \pm 6.3$ & $27.1 \pm 5.7$ & $<0.01$ \\
Total cholesterol $(\mathrm{mg} / \mathrm{dl})$ & $181.7 \pm 37.2$ & $173.7 \pm 37.1$ & $\mathrm{NS}$ \\
HDL-cholesterol $(\mathrm{mg} / \mathrm{dl})$ & $51.5 \pm 6.6$ & $57.3 \pm 5.6$ & $\mathrm{NS}$ \\
LDL-cholesterol $(\mathrm{mg} / \mathrm{dl})$ & $107.1 \pm 22.4$ & $102.6 \pm 31.1$ & $\mathrm{NS}$ \\
Triglycerides $(\mathrm{mg} / \mathrm{dl})$ & $115.5 \pm 61.3$ & $68.5 \pm 28.5$ & $<0.05$ \\
AST $(\mathrm{U} / \mathrm{l})$ & $17.2 \pm 3.5$ & $15.5 \pm 2.5$ & $\mathrm{NS}$ \\
ALT $(\mathrm{U} / \mathrm{l})$ & $18.8 \pm 3.2$ & $13.0 \pm 7.6$ & $\mathrm{NS}$ \\
Glucose $(\mathrm{mg} / \mathrm{dl})$ & $86.8 \pm 10.6$ & $75.0 \pm 6.5$ & $\mathrm{NS}$ \\
Total ACRP30 $(\mu \mathrm{g} / \mathrm{ml})$ & $8.7 \pm 3.5$ & $11.7 \pm 3.5$ & $<0.05$ \\
HMW ACRP30 $(\mu \mathrm{g} / \mathrm{ml})$ & $4.8 \pm 2.4$ & $7.8 \pm 2.5$ & $<0.05$ \\
\hline
\end{tabular}

The statistical significance was established at $P<0.05$. NS, not significant; AST, aspartate aminotransferase; ALT, alanine aminotransferase; HMW, high molecular weight oligomers.

apaired $t$-test. 


\section{RNA extraction and real-time PCR}

Total RNA from VAT and SAT of 19 patients was isolated using TRIzol according to the manufacturer's instructions (Invitrogen Life Technologies), quantified at 260 and $280 \mathrm{~nm}$ absorbance, and validated. The integrity of total RNA was assessed on a denaturing agarose gel stained with ethidium bromide. Retrotranscription of cDNA was started from $1 \mu \mathrm{g}$ of total RNA, $25 \mathrm{mM}$ pd(N)6 random hexamers, $1 \mathrm{mM}$ of each deoxynucleotide triphosphate (Amersham Biosciences), $10 \mathrm{mM}$ dithiothreitol (Invitrogen Life Technologies), $20 \mathrm{U} / \mathrm{ml}$ of RNAguard_RNase Inhibitor (Amersham Biosciences), $1 \times$ Buffer II (Applied Biosystems), $5 \mathrm{mM}$ $\mathrm{MgCl}_{2}$ (Applied Biosystems), and $200 \mathrm{U} / \mathrm{ml}$ of $\mathrm{M}-\mathrm{MLV}$ Reverse Transcriptase (Invitrogen Life Technologies). Samples without RNA were negative controls. Real-time quantitative PCR was performed using standard protocols with a 7900HT Fast Real-time system instrument (Applied Biosystems). The primers, designed with PRIMER 3 Software (freely download at http:// primer3.wi.mit.edu/), were as follows: 5'-CTGGTGAGAAGGGTGAGAAAG-3' and 5'-ACTCCGGTTTCACCGATGTC-3' for ADIPOQ 5'-CACGCCATGGAGAAGATGG-3 ${ }^{\prime}$ and $5^{\prime}$-TCATATGGGATGACCCTGCAAC-3' for ADIPOR 1 ; 5'-TTTGCCACCCCTCAGTATCG-3' and 5'-GGATGATTCCACTCAGGCCT- $3^{\prime}$ for ADIPOR2; and 5'-CGTGCTGCTGACCGAGG-3' and 5'-GAAGGTCTCAAACATGATCTGGGT- ${ }^{\prime}$ for the housekeeping gene $\beta$-actin. The primers were validated by direct sequencing of the obtained PCR products. Gene expression data were obtained using the $\Delta C$ t method. Each mRNA sample was tested two times in triplicate in all tissues.

\section{Western blotting analysis}

Ten micrograms of serum proteins were treated with $1 \times$ Laemmli buffer, heated at $95^{\circ} \mathrm{C}$ for $10 \mathrm{~min}$, and loaded on $10 \%$ SDS-PAGE gel as described $(6,7,23)$. The blots were developed by ECL (Amersham Biosciences) with the use of a Kodak BioMax Light film, digitalized with a scanner (1200 dpi), and analyzed by densitometry with the ImageJ Software (http://rsbweb. nih.gov.ij/). All serum samples were tested two times in duplicate. For SAT and VAT, the samples were lysed and homogenized in RIPA buffer $(20 \mathrm{mM}$ Tris- $\mathrm{HCl}, \mathrm{pH} 7.5$, $150 \mathrm{mM} \mathrm{NaCl}, 10 \%$ glycerol, $1 \mathrm{mM} \mathrm{Na}_{3} \mathrm{VO}_{4}, 1 \mathrm{mM} \mathrm{NaF}$, $1 \%$ Triton X-100, 0.1\% SDS, 1\% sodium deoxycholate, and $1 \mathrm{mM}$ phenylmethylsulphonyl fluoride plus protease inhibitors). To remove fat ring, lysates were centrifuged at $16100 \boldsymbol{g}$ for $10 \mathrm{~min}$. Successively, lysates were incubated on ice for $10 \mathrm{~min}$, vortexed for $45 \mathrm{~s}$, and maintained on ice for $10 \mathrm{~min}$. After centrifugation at 13200 r.p.m. for $15 \mathrm{~min}$ at $4{ }^{\circ} \mathrm{C}$, the supernatants were collected and proteins were quantified by the Bradford method. Twenty-five micrograms of proteins extracted were dissolved in $1 \times$ Laemmli buffer and separated using 10\% SDS-PAGE gel as described (6, 7, 23).
Incubation with ACRP30 (Cell Signaling Technology, Inc., Danvers, MA, USA) and ADIPORs antibodies (Novus Biologicals, Littleton, CO, USA) was performed according to the manufacturer's instructions. Subsequently, the membranes were normalized with $\beta$-actin antibodies (Sigma-Aldrich). Finally, the blots were developed and analyzed as for serum samples. Each sample was tested three times in duplicate.

\section{Gel filtration analysis}

The ACRP30 oligomer pattern was analyzed on a Superdex 200 10/300 GL column connected to a fast protein liquid chromatography system (Amersham Biosciences Biotech) as previously reported (23). In detail, $750 \mu \mathrm{g}$ of total proteins in $250 \mu \mathrm{l}$ were fractionated at $0.5 \mathrm{ml} / \mathrm{min}$ using PBS as elution buffer. Fractions $(250 \mu \mathrm{l})$ were collected and ACRP30 oligomers were tested using ELISA $(20 \mu \mathrm{l})$ and western blotting $(20 \mu \mathrm{l})$. The column was calibrated using apoferritin (440 kDa), amylase (200 kDa), and glyceraldehyde-3-P dehydrogenase (160 and 46 kDa) (SigmaAldrich). This analysis was performed on four controls and ten patients (six at T0 and T1) in duplicate.

\section{Statistical analysis}

Data were analyzed using the SPSS (v 10.0) Software Package (SPSS, Inc., Chicago, IL, USA). The significances of biochemical parameter differences were determined using the Mann-Whitney $U$ test. The $\chi^{2}$ test was used to compare sex ratios. A multiple logistic regression analysis was performed to correct the significant $P$ values obtained by the univariate analysis. The significant correlations were determined using the Spearman's test. The statistical significance was established at $P<0.05$.

\section{Results}

The anthropometric and biochemical characteristics of the severely obese patients and the age-matched control group are given in Table 1 . The analysis of total ACRP30 levels revealed a concentration statistically lower in the severely obese group than in controls who showed a threefold higher amount of ACRP30 $(8.1 \pm 3.6$ vs $28.9 \pm 9.4 \mu \mathrm{g} / \mathrm{ml}, P<0.01)$. For the total ACRP30 levels, we also observed a lower concentration of HMW oligomers in severely obese patients compared with controls $(4.4 \pm 2.2$ vs $5.9 \pm 3.7 \mu \mathrm{g} / \mathrm{ml}, P<0.05)$. The correlation analysis revealed that in the control group, total ACRP30 was negatively correlated with age $\left(r_{\mathrm{s}}=-0.495, \quad P<0.01\right), \quad \mathrm{BMI} \quad\left(r_{\mathrm{s}}=-0.418\right.$, $P<0.01)$, total cholesterol $\left(r_{\mathrm{s}}=-0.304, P=0.05\right)$, triglycerides $\left(r_{\mathrm{s}}=-0.441, \quad P<0.01\right)$, and ALT $\left(r_{\mathrm{s}}=-0.362, P<0.05\right)$, while in obese patients, 
this correlation was evident only with age $\left(r_{\mathrm{s}}=\right.$ $-0.495, \quad P<0.01)$, triglycerides $\quad\left(r_{\mathrm{s}}=-0.448\right.$, $P<0.05)$, and ALT $\left(r_{\mathrm{s}}=-0.438, P<0.05\right)$. Furthermore, in the control group, total ACRP30 was positively correlated with HDL-cholesterol levels $\left(r_{\mathrm{s}}=0.440\right.$, $P<0.01)$. HMW oligomer levels inversely correlated with BMI $\left(r_{\mathrm{s}}=-0.438, P<0.05\right)$, triglycerides $\left(r_{\mathrm{s}}=\right.$ $-0.349, P<0.05)$, AST $\left(r_{\mathrm{s}}=-0.500, P<0.01\right)$, and ALT $\left(r_{\mathrm{s}}=-0.552, P<0.01\right)$ in the control group, whereas only a negative correlation with triglycerides was observed in the obese group $\left(r_{\mathrm{s}}=-0.585\right.$, $P<0.01)$. In the control group, HMW oligomer levels positively correlated with HDL-cholesterol $\left(r_{\mathrm{s}}=0.306\right.$, $P=0.08$ ), although this correlation failed to reach the statistical significance. No correlation was found between HDL-cholesterol or LDL-cholesterol and ACRP30 and HMW oligomers in obese patients.

The anthropometric and biochemical characteristics of the obese patient subgroup subjected to bariatric surgery are given in Table 2. Twelve months after the surgery (T1), all patients showed significant body weight loss and BMI reduction compared with T0 $(P<0.01)$, with a EWL ranged from 25 to $51 \%$. The comparison analysis of total ACRP30 and HMW oligomers between T0 and T1 highlighted that the weight loss was followed by a significant increase in total ACRP30 and HMW oligomer levels $(P<0.05)$. The Spearman's analysis revealed that total ACRP30 at TO shows a positive correlation with total ACRP30 at T1 $\left(r_{\mathrm{s}}=0.600\right.$, $P=0.208$ ), and the HMW oligomer levels at T0 are directly correlated with total ACRP30 at T1 $\left(r_{\mathrm{s}}=0.600\right.$, $P=0.208)$ but inversely correlated with triglycerides at T1 $\left(r_{\mathrm{s}}=-0.600, P=0.208\right)$; however, these correlations failed to reach statistical significance. No correlation was found between HDL-cholesterol or LDL-cholesterol and ACRP30 and HMW oligomers in obese patients subjected to bariatric surgery neither at T0 nor at T1.

The analysis of mRNA and protein expression showed that $A D I P O Q / A C R P 30$ as well as ADIPOR 1 and ADIPOR2 did not differ between VAT and SAT of severely obese subjects (Fig. 1A, B and C). To investigate the profile of ACRP30 oligomers, western blotting was performed under native conditions and three bands corresponding to HMW $(\geq 250 \mathrm{kDa}), \quad \mathrm{MMW}$ $(\sim 180 \mathrm{kDa})$, and LMW $(\sim 90 \mathrm{kDa})$ oligomers were evident for both controls (Fig. 2A, lanes 1-4) and patients (Fig. 2A, lanes 5-8). The densitometric evaluation of the oligomeric distribution still showed a higher expression of the HMW, MMW, and LMW oligomers in controls compared with obese patients (Fig. 2A, $P<0.05)$.

Further investigation of the native distribution and abundance of ACRP30 oligomers was performed by gel filtration. The ELISA of the eluted fractions showed a lower amount of all ACRP30 oligomers in severely obese patients compared with controls (Fig. 2B). Particularly, we observed that forms having molecular weights lower than those of LMW oligomers were also less present in obesity. Western blot relative to FPLC fractions confirmed the same results (Fig. 2B). Western blotting, performed on the serum of the obese patients subjected to bariatric surgery, revealed that the T1 levels of HMW, MMW, and LMW oligomers were higher than the TO levels $(P<0.05$; Fig. 2C).

The ELISA and western blotting of T0 and T1 FPLC fractions also confirmed that the amount of total

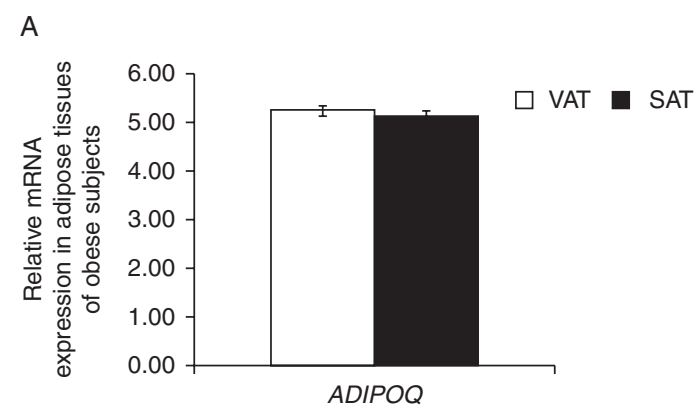

B

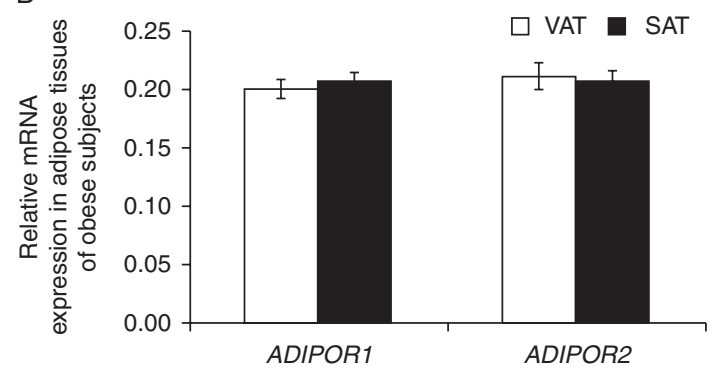

C
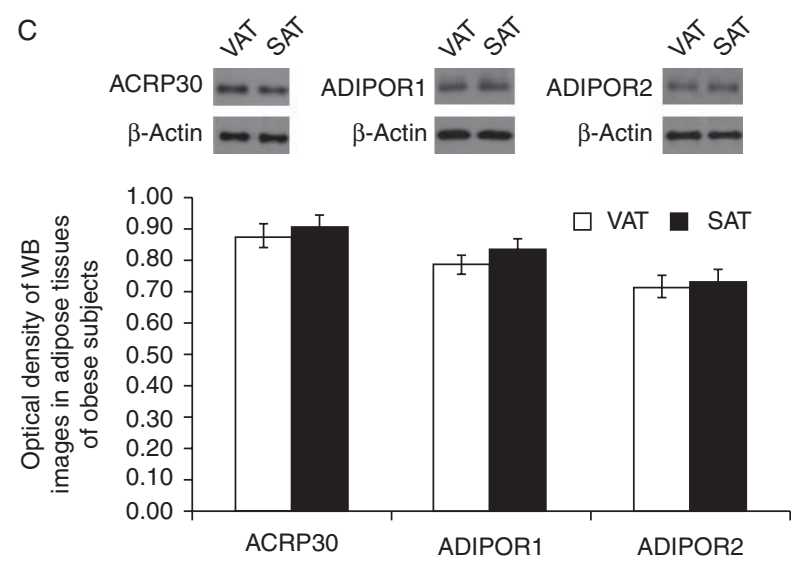

Figure $1 \mathrm{mRNA}$ and protein expression of $A D I P O Q / A C R P 30$, $A D I P O R 1$, and $A D I P O R 2$ in visceral and subcutaneous adipose tissues of severely obese subjects. Real-time PCR of (A) ADIPOQ and (B) ADIPOR1 and ADIPOR2 relative to $\beta$-actin; data are expressed as mean of $2^{-\Delta C t}$ of two independent experiments performed in triplicate. (C) Representative western blotting images of ACRP30, ADIPOR1, and ADIPOR2 with relative $\beta$-actin. Each experiment was performed twice in duplicate. The graphic representation of pixel analysis was performed using ImageJ Software and the values are reported as mean \pm S.D. of two independent experiments performed in duplicate. WB, western blot. 
ACRP30 as well as its oligomeric distribution was increased after weight loss: a different distribution and an abundance of ACRP30 oligomers are evident 12 months after the surgery with a higher amount of all
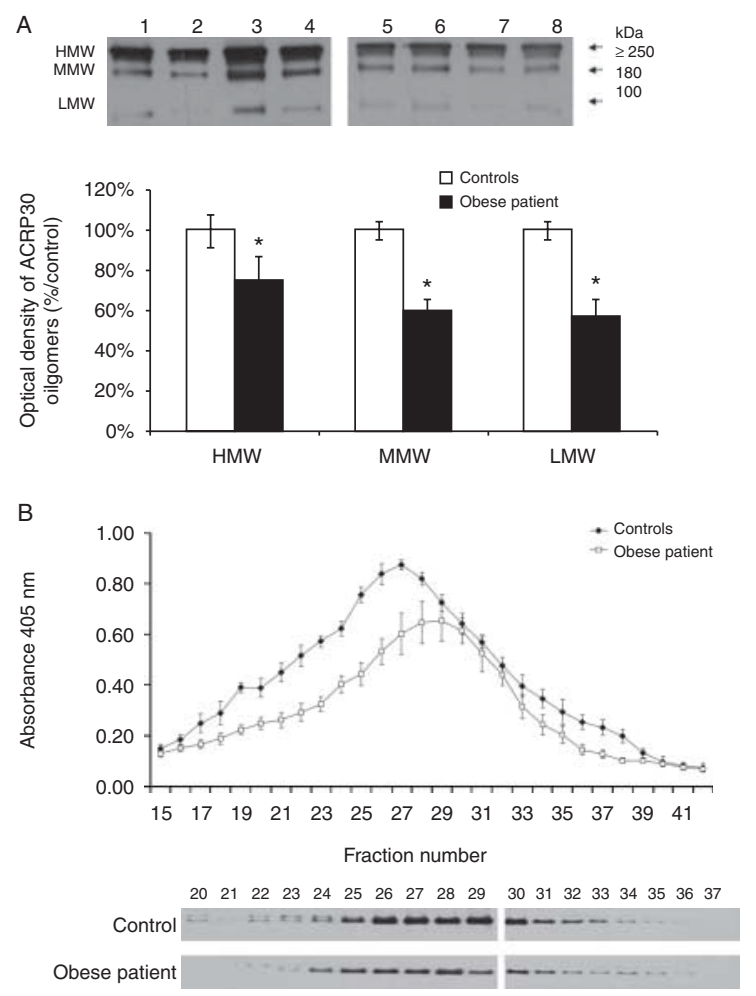

C
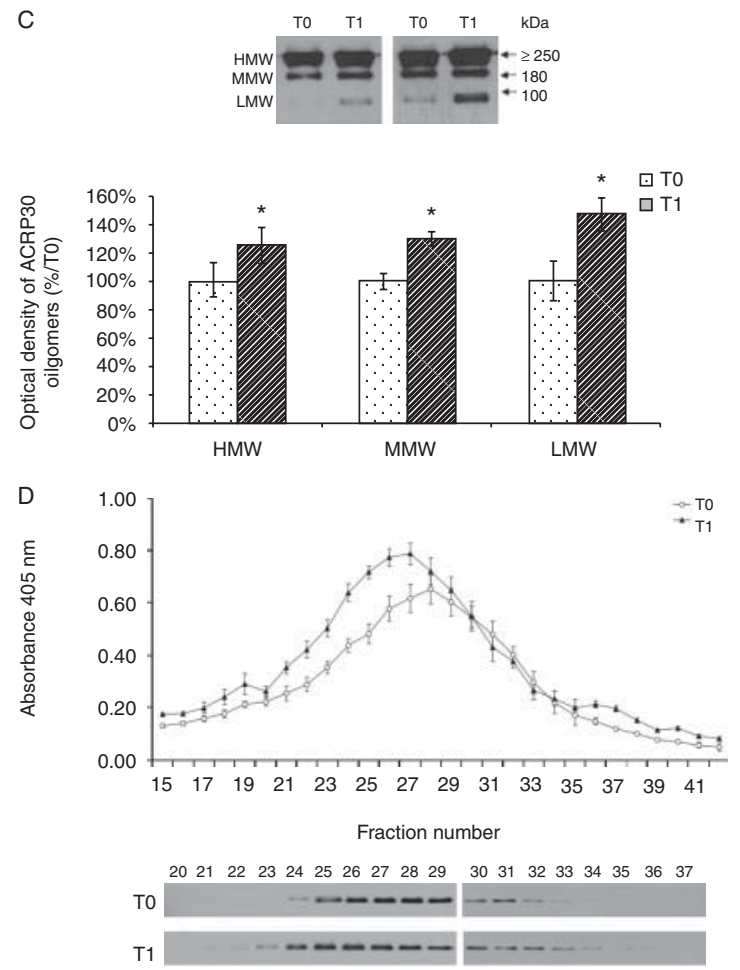

oligomers at T1 (Fig. 2D). Interestingly, a pronounced increase in ACRP30 monomer levels was evident in T1 compared with TO both in ELISA and even more so in western blotting of FPLC fractions.

\section{Discussion}

ACRP30 attracted the interest of many scientists for its antiatherogenic, insulin-sensitizing, anti-inflammatory, and anticancer effects $(1,3,6,14,15)$. ACRP30 is present in serum as different oligomers with biological functions defined not only by their absolute concentrations but also by their distribution $(6,7,8,9)$. The alteration of oligomerization state could be associated with a deregulation of adipose tissue (30). In this study, we investigated circulating total levels of ACRP30 and its whole oligomeric profile and evaluated their association with anthropometric and biochemical parameters of severely obese subjects; we compared obese features with age- and sex-matched control subjects. In addition, we evaluated and compared the same parameters in a subgroup of patients before and after weight loss induced by bariatric surgery. In addition, we compared the expression of ACRP30, ADIPOR1, and ADIPOR2 between VAT and SAT.

Several evidences indicate that both total ACRP30 and HMW oligomer levels decrease in obesity $(31,32,33)$ and increase after weight loss (34). Interestingly, the present study also reveals an involvement of MMW, LMW, and monomeric forms of ACRP30 in the improvement of obesity state. These findings are in line with recent reports in which a role of LMW and MMW oligomers as new biomarkers for obesity-related diseases was proposed (11). In addition, it was also shown that hyperinsulinemia and hyperlipidemia affect total levels of ACRP30 levels modulating MMW and LMW oligomers (10), and after weight loss, an increase in total ACRP30 levels mainly due to LMW forms was also reported (34). However, data about the change in

Figure 2 Western blotting and FPLC gel filtration analyses of ACRP30 and its oligomerization state in serum of controls and severely obese patients $(A$ and $B)$ and of six obese patients subjected to bariatric surgery ( $C$ and $D)$. (A) One representative blot image showing different ACRP30 oligomers (HMW, MMW, and LMW) in controls (lanes 1-4) and in severely obese patients (lanes 5-8). (B) Each fraction's aliquot from FPLC gel filtration was subjected to ELISA and western blotting. The values are reported as mean \pm s.D. of the absorbance at $405 \mathrm{~nm}$ of four controls and four obese patients relative to two independent experiments. (C) One representative blot image of $\mathrm{HMW}, \mathrm{MMW}$, and LMW oligomers in two severely obese patients at TO and T1. (D) Each fraction's aliquot was subjected to ELISA and western blotting analysis. The values are reported as mean \pm s.D. of the absorbance at $405 \mathrm{~nm}$ of six patients at T0 and T1 analyzed in two independent experiments. For western blotting, the graphic representation of pixel analysis was performed using ImageJ Software and the values are reported as mean \pm s.D. of two independent experiments performed in duplicate. The statistical significance was established at ${ }^{*} P<0.05$. 
the distribution of ACRP30 oligomers after surgical weight loss are poor and to some extent conflicting. In fact, some reported no change in total ACRP30 levels but a specific increase in HMW oligomer levels and a decrease in MMW and LMW oligomer levels (28); others showed an increase in total ACRP30 levels mainly due to MMW forms (35), whereas some demonstrated an increase in total ACRP30 levels caused by HMW forms or an increase of only HMW forms $(28,34)$. Our findings showed that with the improvement of obesity state, the level of each ACRP30 oligomer increases, suggesting that the beneficial effects are exerted not only by HMW oligomers but also by other ACRP30 oligomers, including the monomeric form. Previously, it was reported that the monomeric form mainly, through ADIPOR1, stimulates AMPK activation in muscle (36); moreover, gACRP30 was described as a suitable therapeutic molecule as it increased fatty acid oxidation and glucose uptake at the peripheral level (37). Here, the increase of the monomeric form in the serum, after weight loss, confirms the endocrine and paracrine/autocrine role of this specific oligomer and probably could be related to the improvement of the whole-body energy metabolism (24).

Different studies reported that AT differences play a key role in the development of human diseases $(17,19)$. On the other hand, data on ACRP30 expression in relation to AT depot differences are conflicting $(21,22,23)$ even if increased ACRP 30 mRNA levels have been found in VAT vs SAT in animal models $(22,23)$. In the current study, the mRNA as well as the protein expression of ACRP30 and its two receptors did not differ between VAT and SAT in severely obese patients. Accordingly, it was reported that both ACRP30 receptors are similarly expressed between VAT and SAT (25). However, a decreased ADIPOR 1 expression in SAT compared with VAT was also described in obese patients (26). In this study, the reduced circulating levels of ACRP30 seem to be not associated with the adipose tissue depot-specific expression of ACRP30 and its receptors.

In conclusion, our findings suggest that in our cohort of patients, adiposity is associated with the serum concentrations of total ACRP30 and HMW oligomers but not with a different expression of ACRP30 and its receptors between VAT and SAT. Our data confirm the central role of ACRP 30 and its HMW oligomers but interestingly highlight a role of each ACRP30 oligomer in human obesity. The increase of the monomeric form of ACRP30 that could suggest its involvement in the improvement of adipose tissue function after weight loss is noteworthy. Altogether, these data suggest the importance of assessing the whole ACRP30 oligomeric profile as a further potential indicator of adipose tissue functions in obesity. However, further studies are warranted to elucidate the pathophysiological relevance of the distinct expression of ACRP30 oligomers and ADIPORs in adipose tissues in obesity and related diseases.

\section{Declaration of interest}

The authors declare that there is no conflict of interest that could be perceived as prejudicing the impartiality of the research reported.

\section{Funding}

This study was supported by the Regione Campania (D.G.R.C n. 1901 del 22/12/2009), the MIUR (grant number: PS35-126/IND), the IRCCS-SDN Foundation, and the Ministero della Salute.

\section{References}

1 Turer AT \& Scherer PE. Adiponectin: mechanistic insights and clinical implications. Diabetologia $2012552319-2326$. (doi:10.1007/s00125-012-2598-x)

2 Kadowaki $\mathrm{T} \&$ Yamauchi T. Adiponectin and adiponectin receptors. Endocrine Reviews 200526 439-451. (doi:10.1210/ er.2005-0005)

3 Kadowaki T, Yamauchi T, Kubota N, Hara K, Ueki K \& Tobe K. Adiponectin and adiponectin receptors in insulin resistance, diabetes, and the metabolic syndrome. Journal of Clinical Investigation 2006116 1784-1792. (doi:10.1172/JCI29126)

4 Takeuchi T, Adachi Y, Ohtsuki Y \& Furihata M. Adiponectin receptors, with special focus on the role of the third receptor, T-cadherin, in vascular disease. Medical Molecular Morphology 200740 115-120. (doi:10.1007/s00795-007-0364-9)

5 Tsao TS, Tomas E, Murrey HE, Hug C, Lee DH, Ruderman NB, Heuser JE \& Lodish HF. Role of disulfide bonds in Acrp30/adiponectin structure and signaling specificity. Different oligomers activate different signal transduction pathways. Journal of Biological Chemistry $2003 \mathbf{2 7 8} 50810-50817$. (doi:10.1074/jbc.M30 9469200)

6 Daniele A, De Rosa A, Nigro E, Scudiero O, Capasso M, Masullo M, de Laurentiis G, Oriani G, Sofia M \& Bianco A. Adiponectin oligomerization state and adiponectin receptors airway expression in chronic obstructive pulmonary disease. International Journal of Biochemistry \& Cell Biology 201244 563-569. (doi:10.1016/ j.biocel.2011.12.016)

7 Daniele A, De Rosa A, De Cristofaro M, Monaco ML, Masullo M, Porcile C, Capasso M, Tedeschi G, Oriani G \& Di Costanzo A. Decreased concentration of adiponectin together with a selective reduction of its high molecular weight oligomers is involved in metabolic complications of myotonic dystrophy type 1. European Journal of Endocrinology 2011165 969-975. (doi:10.1530/EJE11-0537)

8 Inoue T, Kotooka N, Morooka T, Komoda H, Uchida T, Aso Y, Inukai T, Okuno T \& Node K. High molecular weight adiponectin as a predictor of long-term clinical outcome in patients with coronary artery disease. American Journal of Cardiology $2007 \mathbf{1 0 0}$ 569-574. (doi:10.1016/j.amjcard.2007.03.062)

9 Pajvani UB, Hawkins M, Combs TP, Rajala MW, Doebber T, Berger JP, Wagner JA, Wu M, Knopps A, Xiang AH et al. Complex distribution, not absolute amount of adiponectin, correlates with thiazolidinedione-mediated improvement in insulin sensitivity. Journal of Biological Chemistry $2004 \quad 279$ 12152-12162. (doi:10.1074/jbc.M311113200)

10 Bobbert T, Weicht J, Mai K, Mohlig M, Pfeiffer AF \& Spranger J. Acute hyperinsulinaemia and hyperlipidaemia modify circulating adiponectin and its oligomers. Clinical Endocrinology 200971 507-511. (doi:10.1111/j.1365-2265.2008.03519.x)

11 Hamilton MP, Gore MO, Ayers CR, Xinyu W, McGuire DK \& Scherer PE. Adiponectin and cardiovascular risk profile in patients 
with type 2 diabetes mellitus: parameters associated with adiponectin complex distribution. Diabetes $\mathcal{E}$ Vascular Disease Research 20118 190-194. (doi:10.1177/1479164111407784)

12 Waki H, Yamauchi T, Kamon J, Kita S, Ito Y, Hada Y, Uchida S, Tsuchida A, Takekawa S \& Kadowaki T. Generation of globular fragment of adiponectin by leukocyte elastase secreted by monocytic cell line THP-1. Endocrinology 2005146 790-796. (doi:10.1210/en.2004-1096)

13 Bobbert P, Antoniak S, Schultheiss HP \& Rauch U. Globular adiponectin but not full-length adiponectin induces increased procoagulability in human endothelial cells. Journal of Molecular and Cellular Cardiology 200844 388-394. (doi:10.1016/j.yjmcc. 2007.10.018)

14 Fantuzzi G. Adiponectin and inflammation: consensus and controversy. Journal of Allergy and Clinical Immunology 2008121 326-330. (doi:10.1016/j.jaci.2007.10.018)

15 Lang K \& Ratke J. Leptin and adiponectin: new players in the field of tumor cell and leukocyte migration. Cell Communication and Signaling 200923 7-27. (doi:10.1186/1478-811X-7-27)

16 Fruebis J, Tsao TS, Javorschi S, Ebbets-Reed D, Erickson MR, Yen FT, Bihain BE \& Lodish HF. Proteolytic cleavage product of 30-kDa adipocyte complement-related protein increases fatty acid oxidation in muscle and causes weight loss in mice. PNAS 2001 98 2005-2010. (doi:10.1073/pnas.98.4.2005)

17 Neeland IJ, Turer AT, Ayers CR, Powell-Wiley TM, Vega GL, Farzaneh-Far R, Grundy SM, Khera A, McGuire DK \& de Lemos JA. Dysfunctional adiposity and the risk of prediabetes and type 2 diabetes in obese adults. Journal of the American Medical Association 2012308 150-159. (doi:10.1001/2012.jama.11132)

18 Kovacova Z, Tencerova M, Roussel B, Wedellova Z, Rossmeislova L, Langin D, Polak J \& Stich V. The impact of obesity on secretion of adiponectin multimeric isoforms differs in visceral and subcutaneous adipose tissue. International Journal of Obesity 201236 1360-1365. (doi:10.1038/ijo.2011.223)

19 Matsuzawa Y. The role of fat topology in the risk of disease. International Journal of Obesity 200832 (Suppl 7) S83-S92. (doi:10.1038/ijo.2008.243)

20 Hammes TO, Costa Cdos S, Rohden F, Margis R, de Almeida JC, Padoin AV, Mottin CC \& Guaragna RM. Parallel down-regulation of FOXO1, PPAR $\gamma$ and adiponectin mRNA expression in visceral adipose tissue of class III obese individuals. Obesity Facts 20125 452-459. (doi:10.1159/000339574)

21 Yang WS, Chen MH, Lee WJ, Lee KC, Chao CL, Huang KC, Chen CL, Tai TY \& Chuang LM. Adiponectin mRNA levels in the abdominal adipose depots of nondiabetic women. International Journal of Obesity and Related Metabolic Disorders 200327 896-900. (doi:10.1038/sj.ijo.0802367)

22 Altomonte J, Harbaran S, Richter A \& Dong H. Fat depotspecific expression of adiponectin is impaired in Zucker fatty rats. Metabolism: Clinical and Experimental 200352 958-963. (doi:10.1016/S0026-0495(03)00092-1)

23 Daniele A, Cammarata R, Masullo M, Nerone G, Finamore F, D'Andrea M, Pilla F \& Oriani G. Analysis of adiponectin gene and comparison of its expression in two different pig breeds. Obesity 200816 1869-1874. (doi:10.1038/oby.2008.275)

$24 \mathrm{Lin} \mathrm{H} \mathrm{\&} \mathrm{Li} \mathrm{Z.} \mathrm{Adiponectin} \mathrm{self-regulates} \mathrm{its} \mathrm{expression} \mathrm{and}$ multimerization in adipose tissue: an autocrine/paracrine mechanism? Medical Hypotheses 201278 75-78. (doi:10.1016/j.mehy. 2011.07.063)

25 Nannipieri M, Bonotti A, Anselmino M, Cecchetti F, Madec S, Mancini E, Baldi S, Santini F, Pinchera A, Rossi M et al. Pattern of expression of adiponectin receptors in human adipose tissue depots and its relation to the metabolic state. International Journal of Obesity 200731 1843-1848. (doi:10.1038/sj.ijo. $0803676)$
26 Rasmussen MS, Lihn AS, Pedersen SB, Bruun JM, Rasmussen M \& Richelsen B. Adiponectin receptors in human adipose tissue: effects of obesity, weight loss, and fat depots. Obesity $2006 \mathbf{1 4}$ 28-35. (doi:10.1038/oby.2006.5)

27 Dixon JB, Straznicky NE, Lambert EA, Schlaich MP \& Lambert GW. Surgical approaches to the treatment of obesity. Nature Reviews. Gastroenterology and Hepatology 20118 429-437. (doi:10.1038/ nrgastro.2011.112)

28 Linscheid P, Christ-Crain M, Stoeckli R, Reusch CE, Lutz TA, Muller B \& Keller U. Increase in high molecular weight adiponectin by bariatric surgery-induced weight loss. Diabetes, Obesity $\mathcal{E}$ Metabolism 200810 1266-1270. (doi:10.1111/j.1463-1326. 2008.00899.x)

29 Swarbrick MM, Austrheim-Smith IT, Stanhope KL, Van Loan MD, Ali MR, Wolfe BM \& Havel PJ. Circulating concentrations of high-molecular-weight adiponectin are increased following Rouxen-Y gastric bypass surgery. Diabetologia $2006492552-2558$. (doi:10.1007/s00125-006-0452-8)

30 Mazaki-Tovi S, Romero R, Vaisbuch E, Erez O, Mittal P, Chaiworapongsa T, Kim SK, Pacora P, Yeo L, Gotsch F et al. Maternal serum adiponectin multimers in patients with a smallfor-gestational-age newborn. Journal of Perinatal Medicine 200937 623-635. (doi:10.1515/JPM.2009.128)

31 Daniele A, Cammarata R, Pasanisi F, Finelli C, Salvatori G, Calcagno G, Bracale R, Labruna G, Nardelli C, Buono P et al. Molecular analysis of the adiponectin gene in severely obese patients from southern Italy. Annals of Nutrition and Metabolism 200853 155-161. (doi:10.1159/000172976)

32 Hara K, Horikoshi M, Yamauchi T, Yago H, Miyazaki O, Ebinuma H, Imai Y, Nagai R \& Kadowaki T. Measurement of the high-molecular weight form of adiponectin in plasma is useful for the prediction of insulin resistance and metabolic syndrome. Diabetes Care 200629 1357-1362. (doi:10.2337/dc05-1801)

33 Kaser S, Tatarczyk T, Stadlmayr A, Ciardi C, Ress C, Tschoner A, Sandhofer A, Paulweber B, Ebenbichler CF \& Patsch JR. Effect of obesity and insulin sensitivity on adiponectin isoform distribution. European Journal of Clinical Investigation 200838 827-834. (doi:10.1111/j.1365-2362.2008.02028.x)

34 Benedix F, Westphal S, Patschke R, Granowski D, Luley C, Lippert H \& Wolff S. Weight loss and changes in salivary ghrelin and adiponectin: comparison between sleeve gastrectomy and Roux-en-Y gastric bypass and gastric banding. Obesity Surgery 201121 616-624. (doi:10.1007/s11695-011-0374-5)

35 Engl J, Bobbert T, Ciardi C, Laimer M, Tatarczyk T, Kaser S, Weiss H, Molnar C, Tilg H, Patsch JR et al. Effects of pronounced weight loss on adiponectin oligomer composition and metabolic parameters. Obesity 200715 1172-1178. (doi:10.1038/oby. 2007.627)

36 Tomas E, Tsao TS, Saha AK, Murrey HE, Zhang Cc C, Itani SI, Lodish HF \& Ruderman NB. Enhanced muscle fat oxidation and glucose transport by ACRP30 globular domain: acetyl-CoA carboxylase inhibition and AMP-activated protein kinase activation. PNAS 200299 16309-16313. (doi:10.1073/pnas. 222657499)

37 Almer G, Saba-Lepek M, Haj-Yahya S, Rohde E, Strunk D, Frohlich E, Prassl R \& Mangge H. Globular domain of adiponectin: promising target molecule for detection of atherosclerotic lesions. Biologics 20115 95-105. (doi:10.2147/BTT.S22863)

Received 27 November 2012

Revised version received 26 March 2013

Accepted 23 April 2013 